the GCA cohort vs $36.3( \pm 107.2)$ days in the GnP cohort $(p<0.001)$. Although the mean (SD) daily dose of GC (prednisone equivalent) was similar in both cohorts (27.6 $[ \pm 28.20]$ vs $27.7[ \pm 25.18] \mathrm{mg})$, the mean $(\mathrm{SD})$ cumulative GC dose was significantly higher in the GCA cohort than the GnP cohort $(3503.0( \pm 4622.6) \mathrm{mg}$ vs 503.7 ( \pm 1593.51$) \mathrm{mg} ; p<0.001)$. This indicates that GCA pts had chronic GC exposure over the study period while GnP pts likely utilized higher dose GC burst therapy less frequently. The number of incident complications associated with GC use were significantly greater in the GCA cohort, and included hypertension, diabetes, skin toxicity, infections, neuropsychiatric effects, gastrointestinal complications, ocular effects, and cardiovascular disease $(p<0.05)$.

Conclusion: The overall GC burden in pts with GCA is significantly higher than the general population and may result in downstream complications related to GC exposure. The incidence of GC-related complications was statistically significantly higher in GCA pts compared with GnP pts, even with a short duration of GC use. The early onset of these complications may be a significant contributor to long-term healthcare costs in GCA pts

Acknowledgments: Study and medical writing (provided by Gauri Saal, MA, Economics, Prime, Knutsford, UK, under the direction of authors) were funded by Sanofi, Inc.

Disclosure of Interests: Rajeshwari Punekar Shareholder of: Sanofi, Employee of: Sanofi, Patrick LaFontaine Shareholder of: Sanofi, Employee of: Sanofi, John H. Stone Grant/research support from: Roche, Consultant of: Roche DOI: 10.1136/annrheumdis-2020-eular.4263

\section{OP0276 \\ CLINICAL PATTERNS AND FOLLOW-UP OF INFLAMMATORY ARTHRITIS AND OTHER IMMUNE- RELATED ADVERSE EVENTS INDUCED BY CHECKPOINT INHIBITORS. A MULTICENTER STUDY}

J. A. Gómez-Puerta ${ }^{1}$, C. Perez-Garcia ${ }^{2}$, D. Lobo Prat ${ }^{3}$, R. Gumucio ${ }^{1}$, F. Ojeda ${ }^{2}$, A. M. Millán Arciniegas ${ }^{3}$, S. Rodriguez Garcia ${ }^{1}$, V. Ruiz ${ }^{1}$, H. Corominas ${ }^{3}$. ${ }^{1}$ Hospital Clinic, Rheumatology, Barcelona, Spain; ${ }^{2}$ Hospital del Mar, Rheumatology, Barcelona, Spain; ${ }^{3}$ Hospital de la Santa Creu i Sant Pau, Rheumatology, Barcelona, Spain

Background: Immune checkpoint inhibitors (ICI), such as anti-CTLA-4and anti-PD1/PD-L1 monoclonal antibodies, have produced impressive clinical results in different types of cancer. However, immune-related adverse events (irAEs) may develop a wide spectrum of disabling syndromes. Knowledge of different rheumatic irAEs induced by $\mathrm{ICl}$ is increasing over the last years, however clinical patterns, time to onset of different irAEs according to treatment and follow-up are less well known.

Objectives: To describe different clinical patterns of rheumatic irAEs induced by $\mathrm{ICl}$ and their rheumatic and oncologic outcomes.

Methods: We included consecutive patients with rheumatic irAEs from 3 different referral centers in Barcelona with special emphasis in articular irAEs. Four main clinical syndromes were identified: inflammatory arthritis (IA), non-inflammatory arthralgias (NIA), psoriatic arthritis (PsA)-like and polymialgia (PMR)-like. We conducted a baseline visit and then follow-up in order to determine their clinical pattern, treatment response and outcome. Longitudinal visits were done from January 2017 to January 2020. Patients with other non-articular diagnosis were not included in the follow-up analysis.

Results: We included 55 patients. A total of 34 patients were male $(61.8 \%)$ with a mean age of $65.0 \pm 11.4$ years. Oncologic underlying diagnosis was lung carcinoma in $24(43.6 \%)$ patients, followed by melanoma in $17(29 \%)$, urothelial cancer in 4 (7.3\%), breast in $2(3.6 \%)$ and $2(3.6 \%)$ acute myeloid leukemia among others. Seven $(12.7 \%)$ patients received $\mathrm{ICl}$ as combined therapy. Different $\mathrm{ICI}$ were used including: Pembrolizumab in 21 (38.2\%), Nivolumab 13 (23.6 \%), Atezolizumab 6 (10.9\%), Nivolumab + ipilimumab $5(9.0 \%)$, Durvalumab $3(5.5 \%)$, Pembrolizumab + epacadostat in $2(3.6 \%)$, 2 anti TIM3, Atezolizumab+ Ibatasertib, Avelumab and Ipilimumab in one case each. 12 out of 55 patients had an underlying rheumatic disease before $\mathrm{ICI}$ treatment. Eleven patients developed other irAEs before or at the same time as rheumatic syndromes (mainly colitis and thyroiditis). Main rheumatic irAE included: IA in $23(41.8 \%)$, NIA in 16 (29.1\%), PsA-like in 6 (10.9\%), PMR-like in $5(9.1 \%)$ among others. Time from $\mathrm{ICl}$ to irAEs was $8.3 \pm 8.4$ months $(\mathrm{mo})$. irAE presented earlier in patients with combined $\mathrm{ICI}$ therapy than in patients with monotherapy $(6.5 \pm 4.0$ vs $8.6 \pm 8.9 \mathrm{mo}, \mathrm{p}=\mathrm{NS}$, Figure 1A). Time (in mo) from $\mathrm{ICl}$ initiation to irAE onset was different according to treatments. For Nivolumab $10.0 \pm 10.6$, Anti TIM3 $10.0 \pm 1.4$, Durvalumab 9.0 \pm 2.0 , Ipilimumab 7.98 \pm 9.21 , Pembrolizumab $7.28 \pm 7.53$, Avelumab 6.0 and Atezolizumab $4.4 \pm 5.38 \mathrm{mo}$ (Figure 1B). Time from $\mathrm{ICl}$ initiation and onset also differs among rheumatic irAEs (Figure 2). Mean time follow-up was 13.4 $\pm 10.9 \mathrm{mo}$. At the last visit, $45 \%$ were under GC, mean dose of $3.6 \mathrm{mg} / \mathrm{d}$ (range $0-40$ ). DMARD were needed in $15 \%$ of patients (6 patients MTX, 1 with LEF and $1 \mathrm{SFZ}$ ). At the last visit, 11 (22.9\%) patients remain with persistent arthritis, $25 \%$ intermittent flares and $52 \%$ had a self-limited pattern. Regarding oncologic outcome, $30.2 \%$ were on remission, $30.2 \%$ in partial response and $39.6 \%$ with tumor progression. Eleven (20\%) of patients died.

Conclusion: We described different clinical patterns according treatment and irAEs. Combined ICI therapy and patients treated with Atezolizumab had earlie onset of symptoms. Vasculitis and PMR-like syndromes appear in earlier phases. After a mean follow-up of around 1 year, one-quarter of the patients remain with persistent arthritis and $15 \%$ require DMARD therapy.

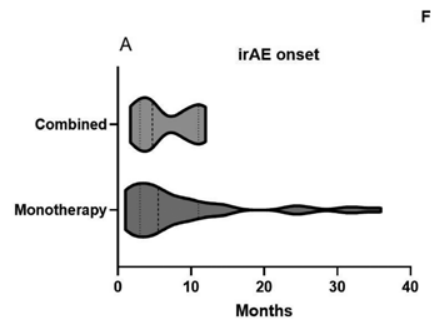

Figure 1

Figure 2

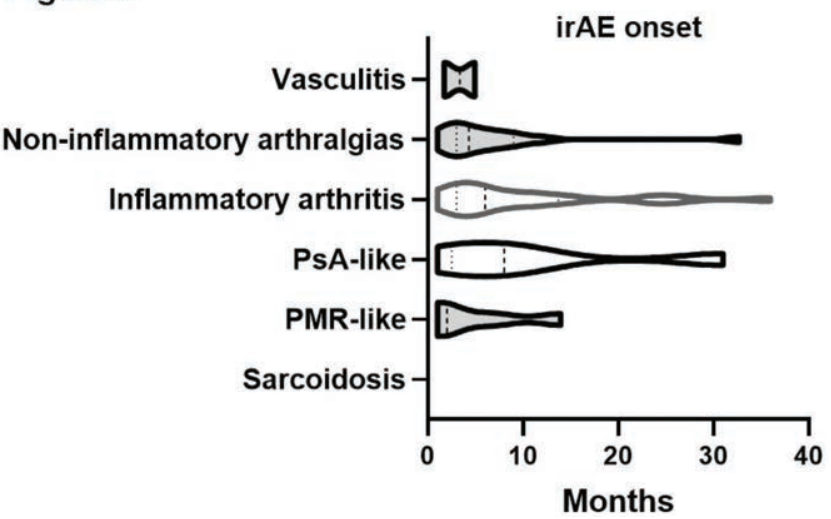

Disclosure of Interests: Jose A. Gómez-Puerta Speakers bureau: Abbvie, BMS, GSK, Lilly, Pfizer, Roche, Carolina Perez-Garcia: None declared, David Lobo Prat: None declared, Roberto Gumucio: None declared, Fabiola Ojeda: None declared, Ana Milena Millán Arciniegas: None declared, Sebastian Rodriguez Garcia: None declared, Virginia Ruiz Speakers bureau: Lilly, Pfizer, Héctor Corominas Speakers bureau: Abbvie, Lilly, Pfizer, Roche DOI: 10.1136/annrheumdis-2020-eular.4308

\section{OP0277 \\ AURORA PHASE 3 STUDY DEMONSTRATES VOCLOSPORIN STATISTICAL SUPERIORITY OVER STANDARD OF CARE IN LUPUS NEPHRITIS (LN)}

C. Arriens ${ }^{1,2}$, S. Polyakova ${ }^{3}$, I. Adzerikho ${ }^{4}$, S. Randhawa ${ }^{5}$, N. Solomons ${ }^{5} .{ }^{1}$ Oklahoma Medical Research Foundation, Oklahoma City, United States of America; ${ }^{2}$ University of Oklahoma Health Sciences Center, Oklahoma City, United States of America; ${ }^{3}$ LLC Medical Center, Kemerovo, Russian Federation; ${ }^{4}$ Minsk Regional Clinical Hospital, Minsk, Belarus; ${ }^{5}$ Aurinia Pharmaceuticals, Victoria, Canada

Background: Voclosporin (VCS) is a novel high potency calcineurin inhibito (CNI) with a favorable metabolic profile and a consistent predictable dose response potentially eliminating the need for therapeutic drug monitoring LN occurs more frequently and is more severe in Hispanic/Latino ethnicity SLE patients. The recently completed phase 3 AURORA study builds on the favorable efficacy seen in the Phase IIb AURA-LV study in patients with active LN.

Objectives: Document efficacy and safety of VCS vs placebo over one year when used with 2 grams of MMF daily and a rapid steroid taper in patients with active LN. Methods: AURORA is a Phase III multicenter, randomized, double-blind, placebo-controlled 52-week study of active LN patients. Patients were randomized 1:1 to VCS (23.7 mg BID) or placebo in combination with mycophenolate (MMF, $1 \mathrm{~g}$ $\mathrm{BID}$ ) and rapidly tapered oral steroids. The primary endpoint was renal response (RR) at 52 weeks, defined as UPCR of $\leq 0.5 \mathrm{mg} / \mathrm{mg}$, eGFR $\geq 60 \mathrm{~mL} / \mathrm{min}$, or no confirmed decrease from baseline in eGFR of $>20 \%$, presence of sustained, low dose steroids and no administration of rescue medication. Ethnicity subgroup analyses of RR was also undertaken given the higher severity of disease in the Hispanic/Latino LN patients.

Results: There were 357 patients enrolled, $88 \%$ female, median age of 31 and $33 \%$ of Hispanic/Latino ethnicity. Renal response by intention to 
treat analysis at 52 weeks was $40.8 \%$ for the voclosporin arm and $22.5 \%$ for the control arm (OR: 2.65; 95\% Cl: 1.64, 4.27; $p<0.001$ ); therefore, AURORA met its primary endpoint. These findings were consistent with those observed in the previously completed pivotal AURA-LV study. Ethnicity subgroup analysis of RR at 52 weeks noted benefit of VCS in both Hispanic/Latino (VCS 38.6\% and control 18.6\%, p=0.0062, OR 3.45) and non-Hispanic/Latino patients (VCS $41.8 \%$ and control $24.6 \%, p=0.0045$, OR $2.29)$. The benefits of VCS were also seen for all pre-specified hierarchical secondary endpoints: RR at 24 weeks, partial renal response (PRR) at 24 and 52 weeks, time to achieve UPCR $\leq 0.5$, and time to $50 \%$ reduction in UPCR. Furthermore, all pre-specified subgroup analyses (age, sex, race, biopsy class, region, and prior MMF use) favored VCS. VCS was well tolerated with no unexpected safety signals. The overall incidence of SAEs were similar in both groups (VCS $20.8 \%$ and control $21.3 \%$ ); with infection most commonly reported (VCS $10.1 \%$ and control $11.2 \%$ ). Overall mortality in the trial was low, with one death in the voclosporin arm and five in the control arm. Additionally, the VCS arm showed no significant decrease at week 52 in eGFR or increase in BP, lipids, or glucose.

Conclusion: The AURORA study met its primary endpoint and VCS was efficacious in Hispanic/Latino ethnicity patients, a difficult to treat group.

Disclosure of Interests: Cristina Arriens Grant/research support from: - BMS: Investigator Initiated Trial Research Funding, GSK: Investigator Initiated Trial Research Funding, Exagen: Research Grant, Consultant of: AstraZeneca (Sci Ad Board Dec 2017), GSK (Sci Ad Board Oct 2018), BMS (Sci Ad Board April 2019), Svetlana Polyakova: None declared, Igor Adzerikho: None declared, Simrat Randhawa Shareholder of: Aurinia Pharmaceuticals, Inc. stock, Employee of: Aurinia Pharmaceuticals, Inc., Neil Solomons Shareholder of: Aurinia Pharmaceuticals, Inc. stock, Employee of: Aurinia Pharmaceuticals.

DOI: 10.1136/annrheumdis-2020-eular.5010

\section{Public health, health services, and health economics in RMDs}

\section{OP0278 IDENTIFICATION OF PARAMETERS ASSOCIATED WITH A DIAGNOSTIC DELAY IN AXIAL SPONDYLOARTHRITIS: RESULTS FROM THE EUROPEAN MAP OF AXIAL SPONDYLOARTHRITIS (EMAS)}

M. Garrido-Cumbrera ${ }^{1,2}$, V. Navarro-Compán ${ }^{3}$, C. Bundy ${ }^{4}$, R. Mahapatra ${ }^{5}$, S. Makri', J. Correa-Fernández ${ }^{1}$, L. Christen ${ }^{7}$, C. J. Delgado-Domínguez ${ }^{1}$, D. Poddubnyy ${ }^{8,9}$ on behalf of EMAS Working Group. ${ }^{1}$ Health \& Territory Research (HTR), Universidad de Sevilla, Sevilla, Spain; ${ }^{2}$ Spanish Federation of Spondyloarthritis Associations (CEADE), Madrid, Spain; ${ }^{3}$ University Hospital La Paz, IdiPAZ, Madrid, Spain; ${ }^{4}$ Cardiff University, Cardiff, United Kingdom; ${ }^{5}$ Axial Spondyloarthritis International Federation (ASIF), London, United Kingdom; ${ }^{6}$ Cyprus League Against Rheumatism, Nicosia, Cyprus; ${ }^{7}$ Novartis Pharma AG, Basel, Switzerland; ${ }^{8}$ Charité-Universitätsmedizin Berlin, Berlin, Germany;

${ }^{9}$ German Rheumatism Research Centre, Berlin, Germany

Background: Early diagnosis of Axial Spondyloarthritis (axSpA) is crucial for timely access to specialist care and effective treatment.

Objectives: To assess the current diagnostic delay in axSpA and identify the parameters associated with increased diagnostic delay in a European sample. Methods: Data from unselected patients participating in the European Map of Axial Spondyloarthritis (EMAS) study through an online survey (2017- 2018) across 13 countries were analysed. Mean differences in diagnostic delay were analysed using Mann-Whitney and Kruskal-Wallis tests, among sociodemographic and disease-related factors. A multivariate linear regression analysis was carried out to identify the relative weight of the associated parameters in determining diagnostic delay.

Results: 2,846 patients participated in EMAS. Mean age was 43.9 years, $61.3 \%$ were female, $48.1 \%$ had a university degree, and $53.9 \%$ were employed. Of the 2846 participants, 2652 provided information for calculating diagnostic delay. Mean age at symptom onset was $26.6 \pm 11.1$, mean age at diagnosis was 33.7 \pm 11.5 , and mean diagnostic delay was $7.4 \pm 8.4$ (Fig. 1). The following variables were associated with longer diagnostic delay in the bivariate analysis: older age, female gender, being diagnosed by a rheumatologist (Table 1). In the multivariate regression analysis younger age at symptom onset, number of HCPs seen before were associated with diagnostic delay (Table 2).
Table 1. Associations between sociodemographic and disease-related variables and diagnostic delay (N: 2,652)

\begin{tabular}{|c|c|c|c|}
\hline Variable & & $\begin{array}{c}\text { Diagnostic Delay (years) } \\
\text { Mean } \pm \text { SD }\end{array}$ & P-value \\
\hline Age categories & $\begin{array}{l}18-34 \\
35-51 \\
52-68 \\
>68\end{array}$ & $\begin{array}{c}4.4 \pm 5.5 \\
7.9 \pm 8.2 \\
9.5 \pm 10.2 \\
7.3 \pm 9.7\end{array}$ & $<0.001$ \\
\hline Gender & $\begin{array}{l}\text { Male } \\
\text { Female }\end{array}$ & $\begin{array}{l}6.1 \pm 7.4 \\
8.2 \pm 8.9\end{array}$ & $<0.001$ \\
\hline Education level & $\begin{array}{l}\text { No school completed } \\
\text { Primary school } \\
\text { High school } \\
\text { University }\end{array}$ & $\begin{array}{l}8.0 \pm 10.7 \\
7.6 \pm 8.9 \\
7.6 \pm 8.4 \\
7.3 \pm 8.3\end{array}$ & 0.397 \\
\hline Occupation & $\begin{array}{l}\text { Manual worker } \\
\text { Non-manual worker }\end{array}$ & $\begin{array}{l}6.7 \pm 8.3 \\
7.3 \pm 8.4\end{array}$ & 0.163 \\
\hline Diagnosed by rheumatologist & $\begin{array}{l}\text { Yes } \\
\text { No }\end{array}$ & $\begin{array}{l}7.9 \pm 8.7 \\
5.7 \pm 7.3\end{array}$ & $<0.001$ \\
\hline HLA-B27 & $\begin{array}{l}\text { Positive } \\
\text { Negative }\end{array}$ & $\begin{array}{l}8.3 \pm 8.3 \\
8.7 \pm 9.0\end{array}$ & 0.775 \\
\hline Uveitis (ever) & $\begin{array}{l}\text { Yes } \\
\text { No }\end{array}$ & $\begin{array}{l}8.0 \pm 8.3 \\
7.6 \pm 8.4\end{array}$ & 0.098 \\
\hline IBD (ever) & $\begin{array}{l}\text { Yes } \\
\text { No }\end{array}$ & $\begin{array}{l}7.7 \pm 8.7 \\
7.5 \pm 8.5\end{array}$ & 0.944 \\
\hline
\end{tabular}

Table 2. Regression analysis between sociodemographic and clinical variables in relation to diagnostic delay

\begin{tabular}{|c|c|c|c|c|}
\hline \multirow[t]{2}{*}{ Variable } & \multicolumn{2}{|c|}{$\begin{array}{l}\text { Univariable linear } \\
\text { regression }\end{array}$} & \multicolumn{2}{|c|}{$\begin{array}{l}\text { Multivariable stepwise } \\
\text { linear regression }\end{array}$} \\
\hline & B & $95 \% \mathrm{Cl}$ & B & $95 \% \mathrm{Cl}$ \\
\hline Age at symptoms onset & -0.289 & $-0.316,-0.262$ & -0.321 & $-0.390,-0.253$ \\
\hline Female gender & 2.099 & $1.442,2.755$ & NA & NA \\
\hline Employed, Manual worker & -0.604 & $-1.953,0.746$ & NA & NA \\
\hline Educational status, University & -0.343 & $-0.986,0.299$ & NA & NA \\
\hline Diagnosed by rheumatologist, Yes & 2.117 & $1.321,2.913$ & NA & NA \\
\hline Number of HCPs seen before diagnosis & 1.723 & $1.486,1.960$ & 1.258 & $0.739,1.776$ \\
\hline HLA-B27, Positive & -0.471 & $-1.347,0.404$ & NA & NA \\
\hline Uveitis (ever), Yes & 0.463 & $-0.392,1.319$ & NA & NA \\
\hline IBD (ever), Yes & 0.123 & $-0.971,1.217$ & NA & NA \\
\hline
\end{tabular}

Conclusion: In this large sample of axSpA patients from 13 different European countries, the average diagnostic delay was more than seven years. The fact that one of the most strongly associated parameters to diagnostic delay was number of HCPs seen before diagnosis suggests the need for urgent action to reduce incorrect referrals to shorten the patient journey to diagnosis across Europe.

Acknowledgments: Funded by Novartis Pharma AG

Disclosure of Interests: Marco Garrido-Cumbrera: None declared, Victoria Navarro-Compán Consultant of: Abbvie, Lilly, Novartis, Pfizer, UCB, Speakers bureau: AbbVie, MSD, Lilly, Novartis, Pfizer, UCB, Christine Bundy Grant/research support from: Has received unrelated honoraria from Abbvie, Celgene, Janssen, Lilly, Novartis, and Pfizer., Raj Mahapatra: None declared, Souzi Makri: None declared, José Correa-Fernández: None declared, Laura Christen: None declared, Carlos

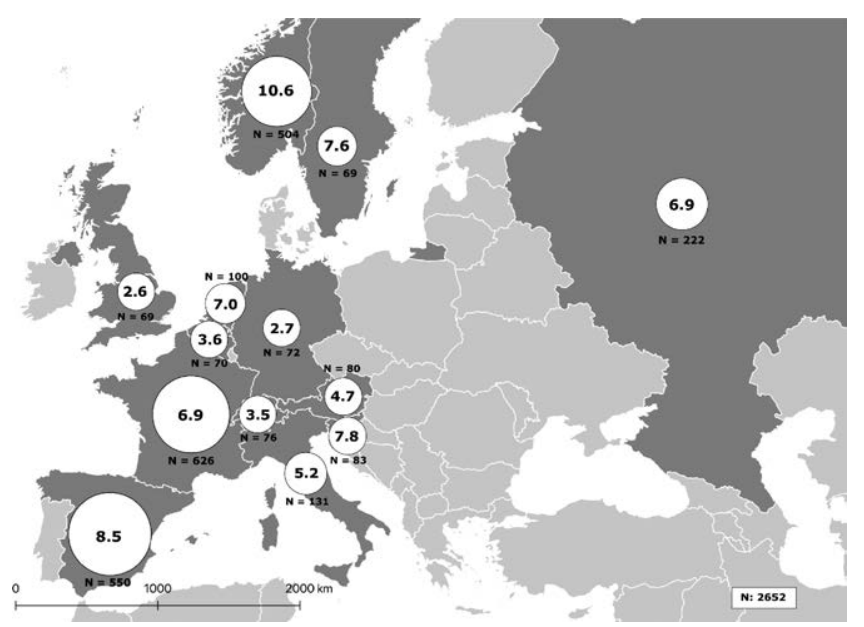

Figure 1. Average years of diagnostic delay across EMAS countries (N:2,652) 